Article

\title{
Ice Surface Temperature Retrieval from a Single Satellite Imager Band
}

\author{
Yinghui Liu ${ }^{1, *}$ (D), Richard Dworak ${ }^{1}$ and Jeffrey Key ${ }^{2}$ \\ 1 Cooperative Institute for Meteorological Satellite Studies, University of Wisconsin-Madison, \\ 1225 West Dayton St., Madison, WI 53706, USA; rdworak@ssec.wisc.edu \\ 2 NOAA/NESDIS, 1225 West Dayton St., Madison, WI 53706, USA; jeff.key@noaa.gov \\ * Correspondence: yinghuil@ssec.wisc.edu; Tel.: +1-608-890-1893
}

Received: 7 October 2018; Accepted: 28 November 2018; Published: 29 November 2018 updates

\begin{abstract}
Current methods for estimating the surface temperature of sea and lake ice-the ice surface temperature (IST) —utilize two satellite imager thermal bands (11 and $12 \mu \mathrm{m})$ at moderate spatial resolution. These "split-window" or dual-band methods have been shown to have low biases and uncertainties. A single-band algorithm would be useful for satellite imagers that have only the $11 \mu \mathrm{m}$ band at high resolution, such as the Visible Infrared Imaging Radiometer Suite (VIIRS), or that do not have a fully functional $12 \mu \mathrm{m}$ band, such as the Thermal Infrared Sensor onboard the Landsat 8 . This study presents a method for single-band IST retrievals, and validation of the retrievals using IST measurements from an airborne infrared radiation pyrometer during the NASA IceBridge campaign in the Arctic. Results show that IST with a single thermal band from the VIIRS has comparable performance to IST with the VIIRS dual-band (split-window) method, with a bias of $0.22 \mathrm{~K}$ and root-mean-square error of $1.03 \mathrm{~K}$.
\end{abstract}

Keywords: sea ice; ice surface temperature; Suomi NPP; JPSS; remote sensing

\section{Introduction}

The surface temperature of sea ice, referred to as ice surface temperature (IST), is one of the most fundamental variables for assessing changes in Arctic climate [1]. Ice surface temperature integrates changes in the surface energy budget, which controls sea ice growth/melt and the exchange of heat and moisture between the surface and the atmosphere. The Arctic is warming at a higher rate than the midlatitudes [2], a pattern known as Arctic amplification. Accurate and consistent measurement of the ice surface temperature across the Arctic is key to understanding Arctic climate change. While measurements at the surface are critical to monitoring climate, they are sparse in polar regions. In contrast, satellite-derived ice surface temperature provides broad spatial coverage, frequent temporal sampling, and relatively high accuracy.

Algorithms have been developed to retrieve IST under clear conditions with longwave infrared bands from satellite imagers. A dual-band regression algorithm utilizes the brightness temperature difference between the "split window" 11 and $12 \mu \mathrm{m}$ thermal bands to account for the atmospheric absorption [3,4]. This approach is most common, and has been applied to retrieve IST using data from the Advanced Very High Resolution Radiometer (AVHRR) [3], the Moderate Resolution Imaging Spectroradiometer (MODIS) [5], and the Visible Infrared Imager Radiometer Suite (VIIRS) onboard the Suomi National Polar-orbiting Partnership (S-NPP) satellite and the Joint Polar Satellite System (JPSS) $[6,7]$. Validation studies have shown good performance, with a root-mean-square error (RMSE) of $1.2 \mathrm{~K}$ or less [5,6,8-12].

Single-band regression algorithms that use the $11 \mu \mathrm{m}$ brightness temperature alone have also been developed to retrieve ice surface temperature, either for the lack of a $12 \mu \mathrm{m}$ band in the earlier 
AVHRR sensors [13,14], or as a backup method if one of the VIIRS thermal window bands fails [7]. Limited validation of these single-band approaches indicates performance similar to the dual-band method [14].

Some practical applications would benefit from the ability to do single-band IST retrievals with high quality. The S-NPP and JPSS VIIRS instruments have 16 moderate resolution bands (M-bands) at $750 \mathrm{~m}$ and five "image" resolution bands (I-bands) at $375 \mathrm{~m}$. The $16 \mathrm{M}$-bands include split-window bands, an $11 \mu \mathrm{m}$ band (M15) with a wavelength range from 10.26 to $11.26 \mu \mathrm{m}$ and a $12 \mu \mathrm{m}$ band (M16) with a wavelength range from 11.54 to $12.49 \mu \mathrm{m}$. The five I-bands include a relatively broad $11 \mu \mathrm{m}$ band (I5) with a wavelength range from 10.5 to $12.4 \mu \mathrm{m}$. The dual-band regression algorithms have been developed utilizing the M15 and M16 bands to retrieve IST at $750 \mathrm{~m}$ resolution [6,7]. Extensive validation studies have shown this product has an absolute bias less than $0.5 \mathrm{~K}$ and an uncertainty less than $1.0 \mathrm{~K}[6,10]$. These IST products are key inputs for other VIIRS ice product algorithms, notably ice concentration and ice thickness $[15,16]$.

While $750 \mathrm{~m}$ ice products are relatively high resolution by today's standards, even higher resolution products are desirable for operational ice applications where small-scale features need to be resolved. VIIRS ice concentration and ice thickness products rely on IST, so it is necessary to create a single-band IST product. Similarly, Landsat 8 has been used in case studies of sea ice for its very high spatial resolution, with $30 \mathrm{~m}$ resolution for visible bands and $100 \mathrm{~m}$ resolution for thermal bands [15]. An IST product from Landsat 8 using either a dual-band or single-band algorithm is desirable for studying sea ice in greater detail, and for deriving other products. Unfortunately, Landsat 8 band $11(12 \mu \mathrm{m})$ has a large uncertainty, thus it is not recommended for quantitative analysis, including retrieval of surface temperature (https: / / landsat.usgs.gov/landsat-8-data-users-handbookappendix-a). Therefore, a single-band regression approach for Landsat 8 IST is also needed.

In this paper we formulate and validate single-band IST products for S-NPP VIIRS and Landsat 8 using high-resolution field survey mission IST measurements. The IST products and their uncertainty information will be useful for monitoring small-scale variations in surface temperature and for generating other high spatial resolution ice products with IST as inputs. We first describe the single-band IST algorithm and the validation dataset, then show the results of the validation.

\section{Materials and Methods}

The dual-band IST algorithm has the following form:

$$
T_{s}=a+b \times T_{11}+c \times\left(T_{11}-T_{12}\right)+d\left(T_{11}-T_{12}\right) \times(\sec \theta-1)
$$

where $T_{\mathrm{s}}$ is the estimated IST $(\mathrm{K}), T_{11}$ and $T_{12}$ are the brightness temperatures $(\mathrm{K})$ at $11 \mu \mathrm{m}$ and $12 \mu \mathrm{m}$ bands, $\theta$ is the sensor scan angle, and $a, b, c$, and $d$ are retrieval coefficients [5,8].

The single-band IST algorithm in previous studies has the following form:

$$
T_{s}=a+b \times T_{11}
$$

where $T_{S}$ is the estimated IST (K), $a$ and $b$ are retrieval coefficients; and $T_{11}$ is the brightness temperature in the $11 \mu \mathrm{m}$ band $(\mathrm{K})[13,14]$. The atmospheric absorption and surface emissivity effects are accounted for implicitly by the coefficients $a$ and $b$. The IST in (1) and (2) is the "skin" temperature, or the radiative temperature of the surface. The ice surface is generally covered with snow, though it may also be bare ice or melt ponds in the summer.

Coefficients of the algorithms can be derived in two ways. One approach is to collocate the satellite brightness temperature with in situ IST measurements, and to determine the retrieval coefficients through linear regression as suggested in [14]. However, collecting sufficient in situ IST measurements with extensive spatial and temporal representation over the sea ice is challenging. The other approach is the use of a forward model as in [3], where a radiative transfer model is used with observed temperature and humidity profiles and a sensor's spectral response functions to simulate the 11 and 
$12 \mu \mathrm{m}$ brightness temperatures that would be observed under a broad range of conditions. We will apply the second approach in this study as described in the following. More details of this approach can be found in $[3,4]$.

A total of 1338 atmospheric temperature and humidity profiles from 1976 to 1991 were sampled from three archives: the North Pole archive, the National Center for Atmospheric Research archive, and the Historical Arctic Rawinsonde archive [17]. These include 553 profiles over the Arctic Ocean and 785 profiles from coastal weather stations. They are more or less evenly distributed over 12 months. All profiles have at least 10 levels of pressure, air temperature, and dew point temperature. VIIRS thermal band response functions for all bands were obtained from the National Oceanic and Atmospheric Administration (NOAA) at https: / / ncc.nesdis.noaa.gov/VIIRS/VIIRSSpectralResponseFunctions.php. The Landsat 8 thermal band response functions were obtained from the National Aeronautics and Space Administration (NASA) at https:/ / landsat.gsfc.nasa.gov/preliminary-spectral-response-of-the-thermalinfrared-sensor/. Here the ice surface is assumed to be snow covered, and the wavelength-dependent snow emissivities were parameterized for all sensor scan angles following the procedure in [18]. Thermal band radiances at $5 \mathrm{~cm}^{-1}$ intervals for scan angels from $0^{\circ}$ to $60^{\circ}$ every $10^{\circ}$ were simulated using the LOWTRAN 7 radiative transfer model [19], with inputs of temperature and humidity profiles and snow emissivity. The temperature at the lowest layer is assigned as the ice surface temperature. The background tropospheric and stratospheric aerosols for subarctic winter and summer were used.

Simulated radiances were integrated for the thermal band based on its response function and then converted to brightness temperature. Linear regression was used to determine the coefficients $a, b, c$, and $d$ in Equation (1) for Landsat 8, and $a$ and $b$ for S-NPP VIIRS I-band I5 and M-band M15, and Landsat 8 band $10(11 \mu \mathrm{m})$ in Equation (2) for three $11 \mu \mathrm{m}$ brightness temperature ranges: less than $240 \mathrm{~K}, 240-260 \mathrm{~K}$, and 260-273 K. Values of the retrieval coefficients and their standard errors are given in Tables 1 and 2. The coefficients for the S-NPP VIIRS dual-band algorithm can be found at https:/ / www.star.nesdis.noaa.gov/jpss / documents / ATBD/ATBD_EPS_Cryosphere_IST_ IceCover_v1.0.pdf. It should be noted that the M15 band covers wavelength from 10.26 to $11.26 \mu \mathrm{m}$, while the $\mathrm{I} 5$ band has a broader wavelength range from 10.5 to $12.4 \mu \mathrm{m}$. Retrieval performance of the single-band algorithm for M15 and 5 may be different due to the differences in wavelength range, although the spatial resolution of retrieval products using 15 band is higher.

Cross-validation was used to test the performance of the retrieval algorithms. Of the 1338 profiles, $90 \%$ were randomly selected to derive the dual-band and single-band retrieval coefficients for Landsat 8 and VIIRS, and the remaining 10\% were used to determine the bias and standard deviation (RMSE nobias $_{\text {) }}$. This process was repeated 100 times. The statistics are shown in Table 3. For the single-band retrieval algorithm in Equation (2), the retrieval biases have a sensor scan angle dependence, e.g., biases range from 0.202 to $-0.480 \mathrm{~K}$ for Landsat 8, from 0.269 to $-0.699 \mathrm{~K}$ for VIIRS M15, and from 0.344 to $-0.819 \mathrm{~K}$ for VIIRS I5 with sensor scan angles from 0 to 60 degree. Also, the differences of retrieved and true surface temperature appear to have linear relationships with column total water vapor (Figure 1). It should be noted that such an angle dependence and linear relationship between retrieval bias and total water vapor for Landsat 8 (Figure 1) and VIIRS (similar as that of Landsat 8, not shown) do not exist for the dual-band retrieval algorithm, as shown in Table 3 and Figure 1. These features suggest an addition of an extra term in the single-band retrieval equation could account for the sensor scan angle dependence. We propose an updated single-band IST retrieval equation:

$$
T_{s}=a+b \times T_{11}+c \times \sec \theta
$$

where $T_{s}$ is the estimated IST, $a, b$, and $c$ are retrieval coefficients, $T_{11}$ is brightness temperature at $11 \mu \mathrm{m}$ band, and $\theta$ is the sensor scan angle. The retrieval coefficients are derived in the same way described above. The addition of the new term alleviates the sensor scan angle dependence of the retrieval bias and the linear relationship between retrieval bias and total water vapor (Table 4, Figure 2). The retrieval coefficients for Equation (3) are listed in Table 5, with their standard errors given in parenthesis. 
Table 1. Landsat 8 dual-band ice surface temperature retrieval coefficients and the standard errors of the coefficients (in parenthesis) in the Arctic as in Equation (1).

\begin{tabular}{cccccc}
\hline Satellite & Temperature Range & $\mathbf{a}(\mathbf{K})$ & $\mathbf{b}$ & $\mathbf{c}$ & $\mathbf{d}$ \\
\hline \multirow{4}{*}{ Landsat 8} & $<240 \mathrm{~K}$ & -0.40 & $1.00(0.019)$ & $1.59(0.53)$ & $-0.76(0.46)$ \\
& $240-260 \mathrm{~K}$ & -0.77 & $1.00(0.0050)$ & $1.51(0.21)$ & $-0.32(0.15)$ \\
& $260-273 \mathrm{~K}$ & -3.49 & $1.01(0.0050)$ & $1.46(0.13)$ & $0.06(0.080)$ \\
\hline
\end{tabular}

Table 2. Suomi National Polar-orbiting Partnership (S-NPP) Visible Infrared Imaging Radiometer Suite (VIIRS) and Landsat 8 single-band ice surface temperature retrieval coefficients and the standard errors (in parenthesis) of the coefficients in the Arctic as in Equation (2).

\begin{tabular}{cccc}
\hline Satellite & Temperature Range & a (K) & b \\
\hline \multirow{3}{*}{ Landsat 8} & $<240 \mathrm{~K}$ & -5.39 & $1.023(0.0047)$ \\
& $240-260 \mathrm{~K}$ & -8.49 & $1.035(0.0088)$ \\
& $260-273 \mathrm{~K}$ & -12.47 & $1.051(0.0046)$ \\
\hline \multirow{2}{*}{ S-NPP VIIRS single-band I5 } & $<240 \mathrm{~K}$ & -8.61 & $1.037(0.0047)$ \\
& $240-260 \mathrm{~K}$ & -15.40 & $1.063(0.0088)$ \\
& $260-273 \mathrm{~K}$ & -14.36 & $1.060(0.0045)$ \\
\hline \multirow{3}{*}{ S-NPP VIIRS single-band M15 } & $<240 \mathrm{~K}$ & -7.25 & $1.031(0.0047)$ \\
& $240-260 \mathrm{~K}$ & -11.56 & $1.048(0.0088)$ \\
& $260-273 \mathrm{~K}$ & -11.78 & $1.049(0.0045)$ \\
\hline
\end{tabular}

Table 3. Bias (top row in a cell) and standard deviation (bottom row in a cell) of the differences between dual-band and single-band ice surface temperature retrievals using Equations (1) and (2) and true ice surface temperatures for Landsat 8 and S-NPP VIIRS in the Arctic.

\begin{tabular}{cccccccc}
\hline \multirow{2}{*}{ Equation } & \multicolumn{7}{c}{ Sensor Scanning Angle (Degree) } \\
\cline { 2 - 8 } & $\mathbf{0}$ & $\mathbf{1 0}$ & $\mathbf{2 0}$ & $\mathbf{3 0}$ & $\mathbf{4 0}$ & $\mathbf{5 0}$ & $\mathbf{6 0}$ \\
\hline \multirow{2}{*}{ Landsat 8 dual-band } & -0.068 & -0.06 & -0.035 & 0.01 & 0.045 & 0.09 & 0.042 \\
& 0.049 & 0.049 & 0.047 & 0.048 & 0.065 & 0.074 & 0.174 \\
\hline \multirow{2}{*}{ Landsat 8 single-band } & 0.202 & 0.192 & 0.163 & 0.107 & 0.017 & -0.132 & -0.480 \\
& 0.194 & 0.193 & 0.190 & 0.186 & 0.189 & 0.226 & 0.437 \\
\hline \multirow{2}{*}{ S-NPP VIIRS dual-band } & -0.017 & -0.02 & -0.017 & -0.008 & 0.028 & 0.124 & -0.088 \\
& 0.137 & 0.138 & 0.139 & 0.143 & 0.152 & 0.183 & 0.392 \\
\hline \multirow{2}{*}{ S-NPP VIIRS single-band M15 } & 0.269 & 0.257 & 0.227 & 0.166 & 0.063 & -0.118 & -0.699 \\
& 0.252 & 0.250 & 0.244 & 0.234 & 0.227 & 0.255 & 0.596 \\
\hline \multirow{2}{*}{ S-NPP VIIRS single-band I5 } & 0.344 & 0.327 & 0.278 & 0.187 & 0.040 & -0.205 & -0.819 \\
& 0.317 & 0.314 & 0.306 & 0.293 & 0.281 & 0.299 & 0.617 \\
\hline
\end{tabular}
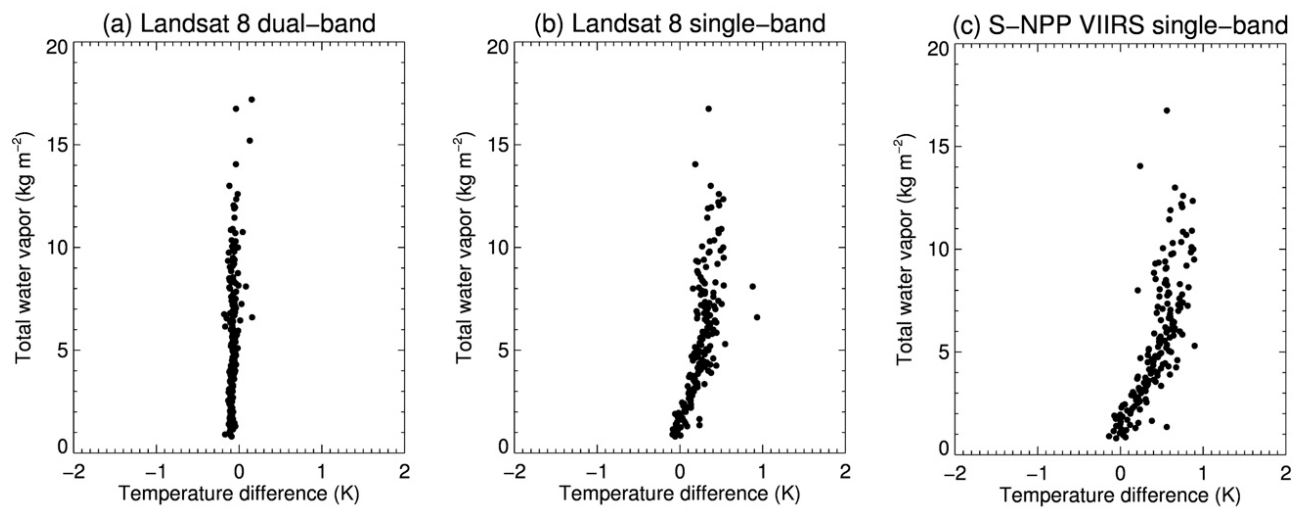

Figure 1. Relationship of the temperature difference between the retrieved and true ice surface temperature and total column water vapor for the (a) Landsat 8 dual-band algorithm using Equation (1), (b) Landsat 8 single-band using Equation (2), and (c) S-NPP VIIRS single-band for I5 band using Equation (2). 
Table 4. Bias (top row in a cell) and standard deviation (bottom row in a cell) of differences between single-band retrievals using Equation (3) and true surface temperatures for Landsat 8 and S-NPP VIIRS in the Arctic.

\begin{tabular}{cccccccc}
\hline \multirow{2}{*}{ Equation } & \multicolumn{7}{c}{ Sensor Scanning Angle (Degree) } \\
\cline { 2 - 8 } & $\mathbf{0}$ & $\mathbf{1 0}$ & $\mathbf{2 0}$ & $\mathbf{3 0}$ & $\mathbf{4 0}$ & $\mathbf{5 0}$ & $\mathbf{6 0}$ \\
\hline \multirow{2}{*}{ Landsat 8 single-band } & -0.030 & -0.028 & -0.019 & -0.004 & 0.021 & 0.067 & 0.054 \\
& 0.156 & 0.156 & 0.157 & 0.165 & 0.186 & 0.242 & 0.363 \\
\hline \multirow{2}{*}{ S-NPP VIIRS single-M-band } & -0.070 & -0.064 & -0.041 & -0.002 & 0.060 & 0.150 & 0.004 \\
& 0.178 & 0.177 & 0.174 & 0.178 & 0.206 & 0.279 & 0.460 \\
\hline \multirow{2}{*}{ S-NPP VIIRS single-I-band } & -0.061 & -0.057 & -0.038 & -0.003 & 0.06 & 0.149 & 0.040 \\
& 0.220 & 0.219 & 0.217 & 0.225 & 0.262 & 0.333 & 0.541 \\
\hline
\end{tabular}

(a) Landsat 8 single-band

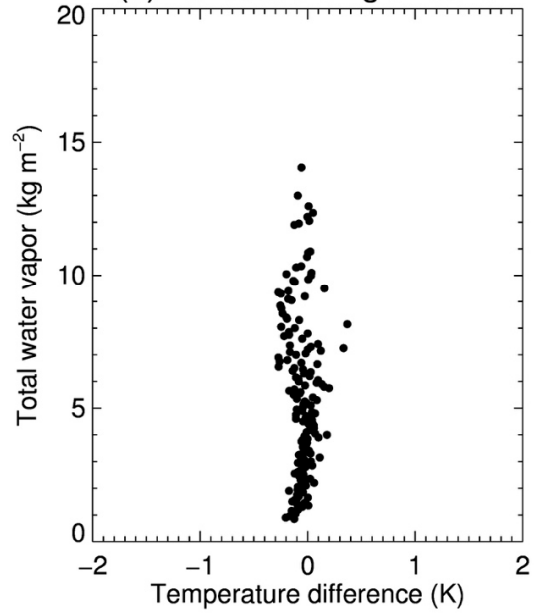

(b) S-NPP VIIRS single-band

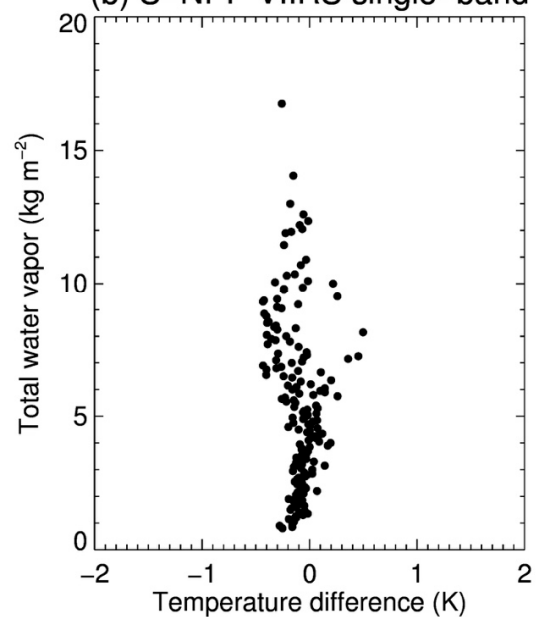

Figure 2. Relationship of the temperature difference between the retrieved and true ice surface temperature and total column water vapor for (a) Landsat 8 single-band algorithm, and (b) S-NPP VIIRS single-band for I5 band using Equation (3).

Table 5. S-NPP VIIRS and Landsat 8 single-band ice surface temperature retrieval coefficients and the standard errors (in parenthesis) of the coefficients in the Arctic as in Equation (3).

\begin{tabular}{ccccc}
\hline Satellite & Temperature Range & $\mathbf{a ~ ( K )}$ & $\mathbf{b}$ & $\mathbf{c}$ \\
\hline \multirow{2}{*}{ Landsat 8} & $<240 \mathrm{~K}$ & 4.92 & $1.020(0.017)$ & $0.147(0.12)$ \\
& $240-260 \mathrm{~K}$ & -7.93 & $1.031(0.0035)$ & $0.505(0.056)$ \\
& $260-273 \mathrm{~K}$ & -15.19 & $1.054(0.0046)$ & $1.438(0.047)$ \\
\hline \multirow{2}{*}{ S-NPP VIIRS } & $<240 \mathrm{~K}$ & -7.29 & $1.029(0.017)$ & $0.316(0.11)$ \\
single-band I5 & $240-260 \mathrm{~K}$ & -12.65 & $1.048(0.0035)$ & $0.943(0.055)$ \\
& $260-273 \mathrm{~K}$ & -21.89 & $1.076(0.0045)$ & $2.550(0.045)$ \\
\hline \multirow{2}{*}{ S-NPP VIIRS } & $<240 \mathrm{~K}$ & -6.51 & $1.027(0.018)$ & $0.149(0.12)$ \\
single-band M15 & $240-260 \mathrm{~K}$ & -10.37 & $1.040(0.0035)$ & $0.727(0.056)$ \\
& $260-273 \mathrm{~K}$ & -16.55 & $1.057(0.0045)$ & $2.055(0.046)$ \\
\hline
\end{tabular}

The primary validation dataset in this study consists of IST measurements made with an airborne Heitronics KT-19.85 Series II infrared radiation pyrometer, hereinafter simply "KT-19", flown on a NASA P3 aircraft during the NASA Operation IceBridge campaigns (https://www.nasa.gov/ mission_pages/icebridge/mission/) [20]. The surface temperature measured by the KT-19 is provided by the IceBridge science team in a dataset available from the National Snow and Ice Data Center (NSIDC; https://nsidc.org/data/iakst1b). The KT-19 measurements have a temperature resolution of $\pm 0.1^{\circ} \mathrm{C}$ and an accuracy of $\pm 0.5^{\circ} \mathrm{C}$ plus $0.7 \%$ of the difference between target temperature and 
KT-19's internal temperature [21] (https:/ / www.wintron.com/heitronics-kt19-infrared-thermometer). The internal temperature may vary as much as $30^{\circ} \mathrm{C}$ during the course of a flight; no correction for these changes has been applied to the KT-19 surface temperature data. The P3 aircraft usually flies only a few hundred meters above ground level, so atmospheric absorption is minimal because of the low water vapor content over sea ice, though it may not be negligible. In deriving surface temperature from KT-19 measurements, the IceBridge science team used a surface emissivity of 0.97 starting in 2012. Before 2012, a surface emissivity of 1.0 was used. This change by the IceBridge team suggests that 0.97 provides the best estimate of surface temperature [21]. More details of KT-19 surface temperature measurements can be found in IceBridge Data Products Manual [21]. All these factors contribute to the overall uncertainty in the KT-19 measurements, which has not been assessed extensively. Previous validation studies show close agreement between KT-19 measurements and dual-band IST retrievals [6,10], and between dual-band IST retrievals and other validation data sets $[5,8,9,11,12]$, which indicates the usefulness of KT-19 measurements in IST validation.

All available cases of KT-19 observations in the Arctic from 2013 to 2017 were used to validate the collocated S-NPP VIIRS and Landsat 8 retrieved IST [22]. Also, a rigorous visual check of both cloud mask products was done to ensure that only clear observations were used. The VIIRS and Landsat 8 cloud masks and a visual inspection of the data were applied to eliminate cloudy and foggy cases for both satellite datasets and the KT-19 [23]. All available KT-19 temperature measurements within $100 \mathrm{~m}$ (Landsat) or $375 \mathrm{~m}$ (VIIRS) of the center of the pixel were averaged. The maximum time difference for matchups between KT-19 and S-NPP VIIRS and Landsat 8 was $60 \mathrm{~min}$. This time difference can contribute to the overall differences between the satellite-retrieved IST and the KT-19 temperature shown below due to surface temperature changes over $60 \mathrm{~min}$.

\section{Results}

On 19 March 2014 from 2237-2238 UTC, a concurrent Landsat 8 overpass and an Ice-Bridge P-3 flight off the Northwest coast of Alaska near Point Lay were acquired (Figure 3). Only clear pixels over sea ice in Landsat 8 were used in analysis. The clear area was determined with the cloud mask, a high value of the Normalized Difference Snow Index (NDSI), and visual inspection. Comparison with KT-19 measurements showed a very small overall cold bias of $-0.03 \mathrm{~K}$, and an RMSE $\mathrm{nobias}_{\text {of }} 0.76 \mathrm{~K}$ (Figure 4). Towards to the end of the KT-19 track, possible cloud contamination near cloud edges in the Landsat 8 data led to lower retrieved IST (Figures 3 and 4).
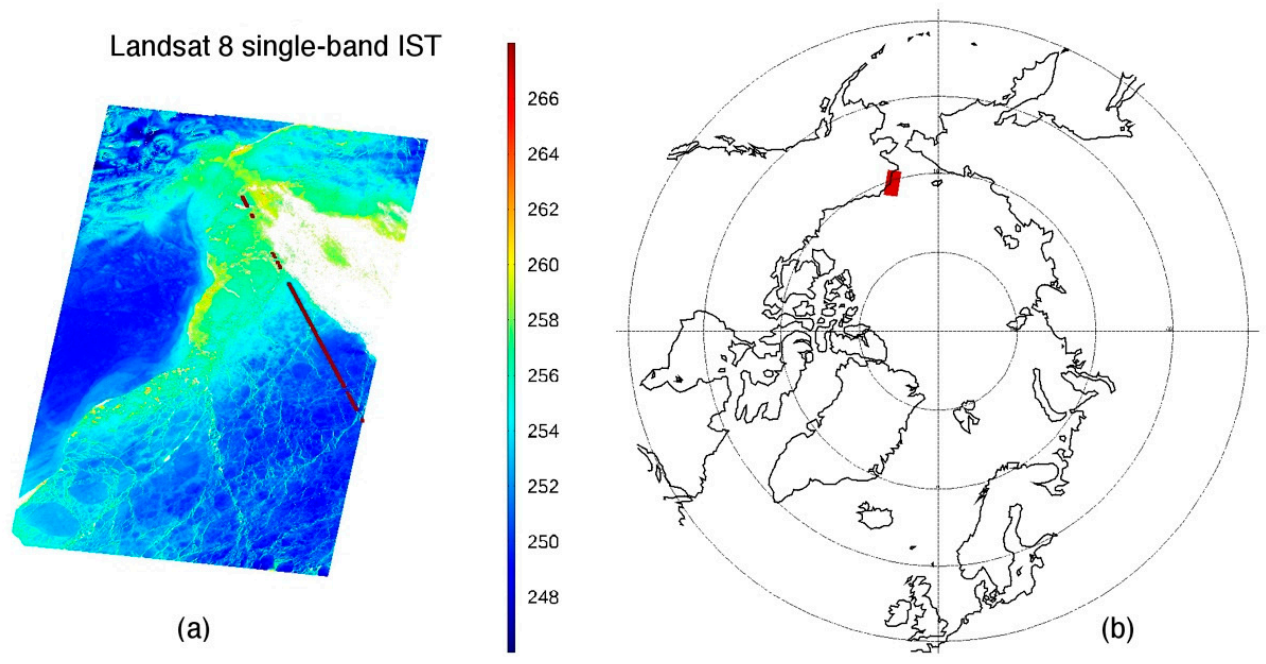

Figure 3. Landsat retrieved ice surface temperature (IST) with a P-3 Ice Bridge flight overlaid (red line) from 22:37-22:38 UTC on 19 March 2014 (a), off the Northwest coast of Alaska (b). The white color in IST field represents cloud cover. 


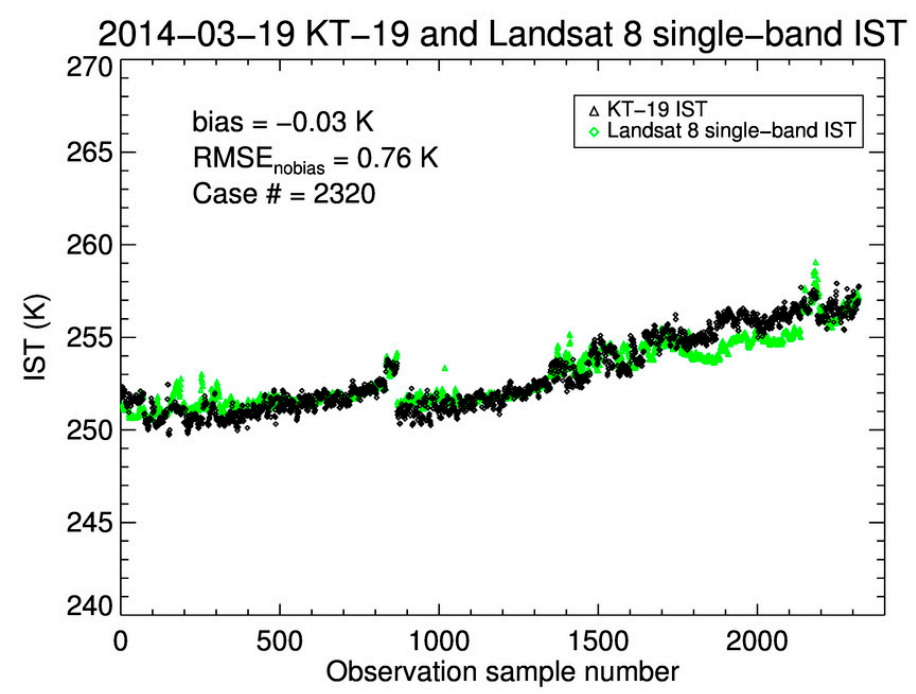

Figure 4. KT-19 ice surface temperature (IST) (black) and retrieved IST from Landsat 8 (green) along the P-3 Ice Bridge flight track from 22:37-22:38 UTC on 19 March 2014.

A mostly clear scene over the Beaufort Sea when an Ice Bridge flight coincided with a S-NPP VIIRS overpass on 30 Mar 2015 was also analyzed (Figure 5). The S-NPP VIIRS derived IST from the M-band dual-band approach [6], and from the single-band approach using the 15 band $(11 \mu \mathrm{m})$ covered the same area. The dual-band IST was quality controlled to screen out clouds with the VIIRS M-band cloud mask (there is no I-band cloud mask) and visual inspection (Figure 5); I-band IST used the same cloud screening. Compared to the dual-band IST, the single-band IST at image resolution shows more detail of the sea ice leads (fractures) because of its higher spatial resolution. The time difference of KT-19 and VIIRS ISTs was 30 min or less for the comparison in Figures 6 and 7. The inter-comparison of VIIRS retrieved IST and KT-19 IST showed very small biases and RMSE $E_{\text {nobias }}$ for both approaches, with a bias of $0.29 \mathrm{~K}$ and $\mathrm{RMSE}_{\text {nobias }}$ of $0.58 \mathrm{~K}$ for the dual-band approach and a bias of $-0.14 \mathrm{~K}$ and $\mathrm{RMSE}_{\text {nobias }}$ of $0.62 \mathrm{~K}$ for the single-band approach.
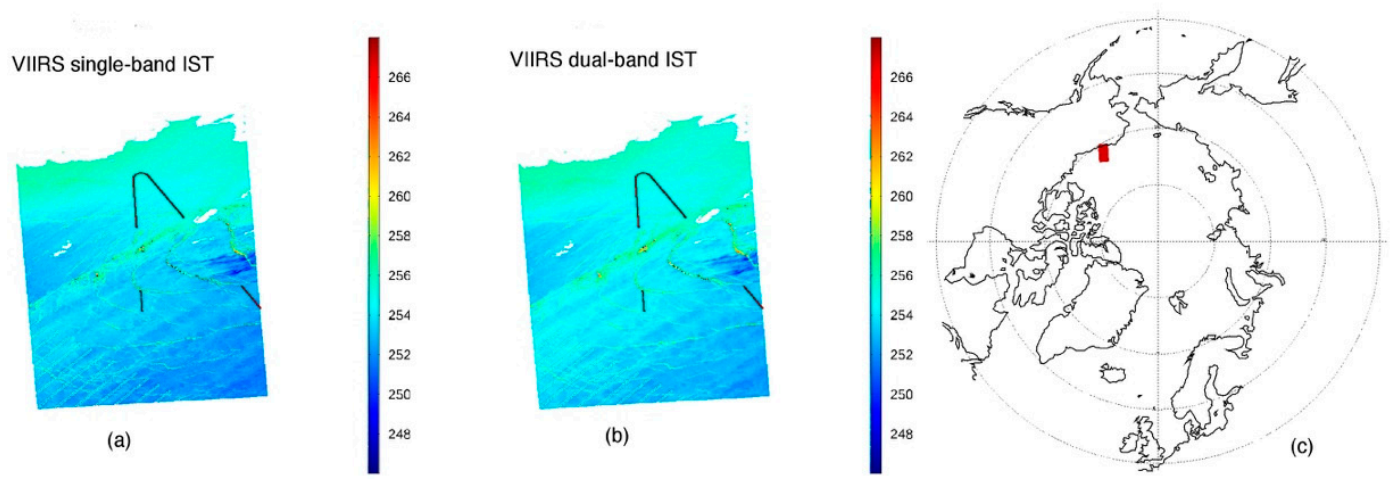

Figure 5. VIIRS IST with the single-band approach using the I-5 band (a) and with the M-band dual-band approach (b), with the IceBridge flight shown (red line) around 22:17 UTC on 30 March 2015 off the North coast of Alaska (c). The white color in IST field represents cloud cover in the M-band cloud mask. 


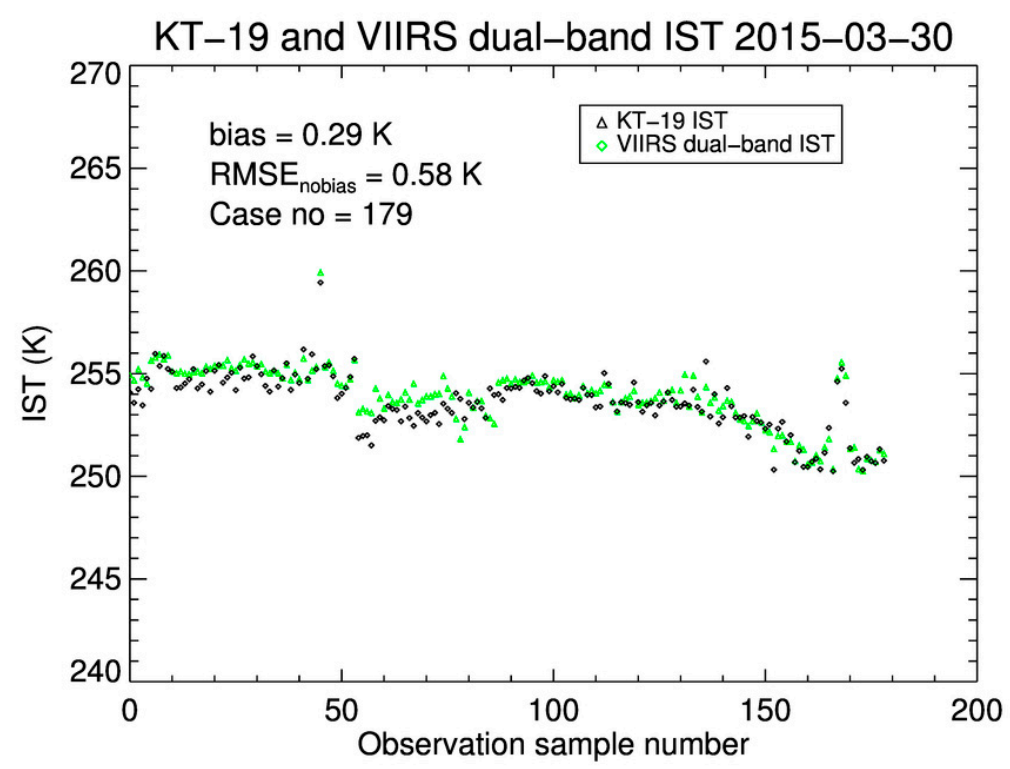

Figure 6. KT-19 ice surface temperature (IST) (black) and dual-band IST from S-NPP VIIRS (green) along the P-3 Ice Bridge flight track around 22:17 UTC on 30 March 2015.

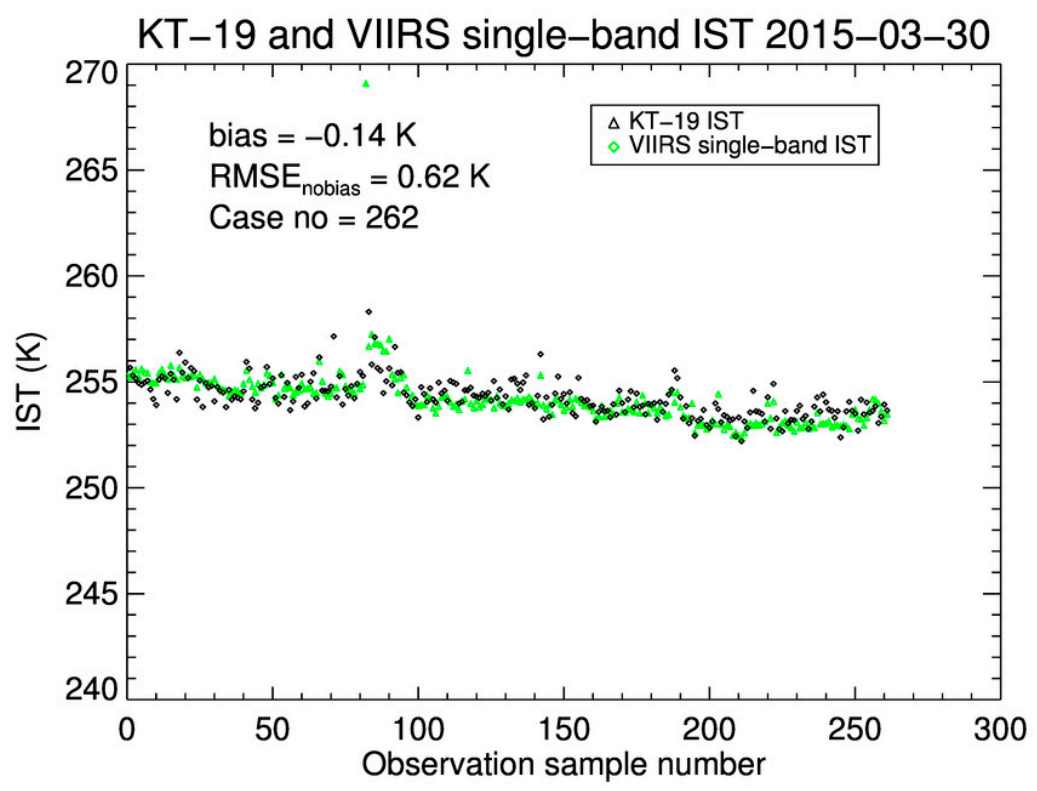

Figure 7. KT-19 ice surface temperature (IST) (black) and single-band IST from S-NPP VIIRS (green) along the P-3 Ice Bridge flight track around 22:17 UTC on 30 March 2015.

Besides the case studies, we also collected all 809 collocated cases of KT-19 and VIIRS ISTs from 2013 to 2017 covering a large area of the Arctic. For easier comparison, both dual-band and single-band VIIRS ISTs were calculated using the M-band brightness temperature. The comparison results are shown in Figure 8. A comparison of these 809 collocated KT-19 IST measurements and VIIRS derived ISTs gave an overall bias of $0.28 \mathrm{~K}$ and a RMSE $\mathrm{E}_{\text {nobias }}$ of $0.99 \mathrm{~K}$ for the dual-band algorithm, and an overall bias of $0.22 \mathrm{~K}$ and $\mathrm{RMSE}_{\text {nobias }}$ of $1.03 \mathrm{~K}$ for the single-band algorithm. The positive biases for both approaches increased slightly with increasing $11 \mu \mathrm{m}$ brightness temperature. To investigate the remaining impacts of the atmospheric effect in the retrieval bias we calculated the correlations between the retrieval bias, the difference of retrieved IST and KT-19 IST, and KT-19 IST, which is a proxy of total column water vapor. The correlations are -0.08 and -0.13 for dual-band and single-band algorithms, which indicates that the atmospheric effect can only explain $0.6 \%$ and $1.7 \%$ of the variance in the retrieval bias for dual-band and single-band algorithms. Both algorithms compensate for the 
atmospheric effects reasonably well. Calculations also show that both bias and RMSE $\mathrm{nobias}_{\text {are not }}$ dependent upon the satellite sensor scan angle.

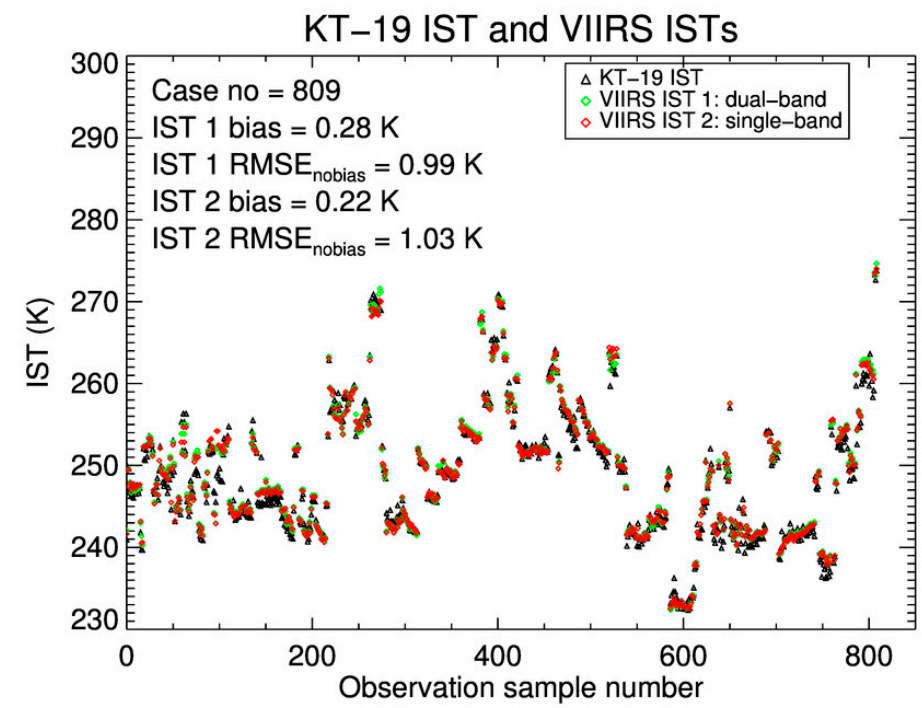

Figure 8. Comparison of IceBridge KT-19 ice surface temperature (IST) and VIIRS derived IST from various scenes using dual-band and single-band algorithms from the S-NPP moderate resolution bands.

\section{Discussion}

Comparison of satellite-derived IST with KT-19 measurements has its limitations. The spatial resolutions of VIIRS and Landsat 8 pixels at nadir are $375 \mathrm{~m}$ for the I-bands (750 $\mathrm{m}$ for M-bands) and $100 \mathrm{~m}$, respectively, while the KT-19 is a $15 \mathrm{~m}$ point-track observation. The collocation of derived ISTs and averaged KT-19 measurements are not always optimal, as the observations of VIIRS, Landsat 8 and KT-19 are not always concurrent in time and cloud contamination may introduce biases and larger uncertainties in the satellite-retrieved ISTs.

Our use of LOWTRAN 7 is primarily a function of heritage, as our earlier work also used this model $[3,4]$. More advanced radiative transfer models are available, primarily providing higher spectral resolution, e.g., the community radiative transfer model (CRTM) and MODTRAN5 [24,25]. Previous tests with MODTRAN5, however, did not indicate that the resulting IST regression coefficients would result in significantly more accurate retrievals.

The dual-band retrieval approach is expected to perform better than the single-band approach because the split-window difference accounts for atmospheric absorption, especially under warmer and more moist conditions. The single-band retrieval approach is therefore expected to be more sensitive to the atmospheric effect and surface emissivity variations. However, results in this study show that both single-band and dual-band retrieval biases do not have an apparent dependence on total column water or sensor scan angle. This might be due to (1) both algorithms have a term related to the sensor scan angle specifically to account for the scan angle and column water vapor effects; and (2) the column water vapor in the Arctic is low, thus its effect on the retrieval is small. In deriving the retrieval coefficients, surface emissivity is prescribed as a function of satellite viewing angle. Snow emissivity changes with snow grain size and shape, and thus depends on surface snow type [26]. Both single-band and dual-band algorithms have been developed to retrieve land surface temperature with an explicit dependence on the surface emissivity [27]. With prior knowledge of surface type and thus surface emissivity, a similar approach can be applied to retrieve the ice surface temperature. Whether this algorithm can be used to retrieval surface temperature over other surface types needs further investigation [28].

It should be acknowledged that there has not been a robust assessment of the uncertainty of the KT-19 surface temperature measurements. The overall bias and RMSE $E_{\text {nobias }}$ of the single-band and dual-band IST retrievals may need to be refined when additional information becomes available on the 
KT-19 absolute bias and uncertainty. However, the lack of information on the absolute KT-19 surface temperature uncertainty does not change the conclusion of this study that the single-band IST retrieval approach can provide results comparable to traditional dual-band IST retrieval approach.

In this study the retrieval coefficients were derived using atmospheric profiles in the Arctic, and performance of the retrievals were evaluated with KT-19 measurements in the Arctic. The application of the same retrieval algorithm on sea ice in the Antarctic is valid because of the similar surface snow type and relatively low water vapor content in the Antarctic. For the same reason, the retrieval algorithm may be applicable to estimating lake ice surface temperature. However, the application of the methods described above over the Antarctic continent and over lake ice needs to be evaluated using in situ measurements and other remote sensed observations with comparable or higher spatial resolution (for example KT-19 measurements) in order to obtain a quantitative assessment of the retrieval algorithm performance. It is possible that new retrieval coefficients would be needed based on atmospheric profiles collected over high-altitude portions of Antarctica and over or near lakes.

\section{Conclusions}

Methods for estimating ice surface temperature from space using a split-window approach similar to those for sea surface temperature have been available since the early 1990's (Key and Haefliger 1992). However, a single-band approach is desirable for special cases, notably for the VIIRS instrument that has a higher resolution band at $11 \mu \mathrm{m}$ but no corresponding $12 \mu \mathrm{m}$ band, and for Landsat 8 where the $12 \mu \mathrm{m}$ band has a large calibration uncertainty. The higher-resolution VIIRS I-band $(375 \mathrm{~m})$ is particularly attractive for operational ice applications where small-scale features are important.

In this study, we developed and validated VIIRS and Landsat 8 IST algorithms that utilize a single thermal band at $11 \mu \mathrm{m}$. For VIIRS IST, a comparison with KT-19 IST measurements in the Arctic from 2013-2017 showed an overall bias of $0.22 \mathrm{~K}$ and RMSE $E_{\text {nobias }}$ of $1.03 \mathrm{~K}$, with only a slightly higher uncertainty than those of dual-band IST. Limited case studies of Landsat 8 IST showed similarly low bias and uncertainty values. The IST from the single-band approach can provide high-quality inputs to algorithms that estimate other sea ice characteristics, such as sea ice concentration and thickness.

Author Contributions: Conceptualization and methodology, Y.L. and J.K.; software, validation and analysis, Y.L. and R.D.; writing—original draft preparation, Y.L. and R.D.; writing—review and editing, Y.L. and J.K.

Funding: This research was funded by NOAA, grant number NA15NES4320001.

Acknowledgments: This work was supported by the JPSS Program Office and the GOES-R Program Office. We thank the anonymous reviewers for their valuable comments and suggestions. The views, opinions, and findings contained in this report are those of the author(s) and should not be construed as an official National Oceanic and Atmospheric Administration or U.S. Government position, policy, or decision.

Conflicts of Interest: The authors declare no conflict of interest.

\section{References}

1. Chapman, W.L.; Walsh, J.E. Simulations of arctic temperature and pressure by global coupled models. J. Clim. 2007, 20, 609-632. [CrossRef]

2. Manabe, S.; Spelman, M.J.; Stouffer, R.J. Transient responses of a coupled ocean-atmosphere model to gradual changes of atmospheric $\mathrm{CO}_{2}$. Part II: Seasonal response. J. Clim. 1992, 5, 105-126. [CrossRef]

3. Key, J.; Haefliger, M. Arctic ice surface-temperature retrieval from avhrr thermal channels. J. Geophys. Res. Atmos. 1992, 97, 5885-5893. [CrossRef]

4. Key, J.R.; Collins, J.B.; Fowler, C.; Stone, R.S. High-latitude surface temperature estimates from thermal satellite data. Remote Sens. Environ. 1997, 61, 302-309. [CrossRef]

5. Hall, D.K.; Key, J.R.; Casey, K.A.; Riggs, G.A.; Cavalieri, D.J. Sea ice surface temperature product from modis. IEEE Trans. Geosci. Remote Sens. 2004, 42, 1076-1087. [CrossRef] 
6. Key, J.R.; Mahoney, R.; Liu, Y.; Romanov, P.; Tschudi, M.; Appel, I.; Maslanik, J.; Baldwin, D.; Wang, X.; Meade, P. Snow and ice products from suomi npp viirs. J. Geophys. Res. Atmos. 2013, 118, 12816-12830. [CrossRef]

7. Baker, N. Joint Polar Satellite System (JPSS) VIIRS Sea Ice Characterization Algorithm Theoretical Basis Document (ATBD). 2011. Available online: http://npp.gsfc.nasa.gov/sciencedocs/2015-06/474-00047_ VIIRS_Sea_Ice_ATBD_Rev-20110422.pdf (accessed on 1 June 2018).

8. Key, J.; Maslanik, J.A.; Papakyriakou, T.; Serreze, M.C.; Schweiger, A.J. On the validation of satellite-derived sea ice surface temperature. Arctic 1994, 47, 280-287. [CrossRef]

9. Scambos, T.A.; Haran, T.M.; Massom, R. Validation of avhrr and modis ice surface temperature products using in situ radiometers. Ann. Glaciol. 2006, 44, 345-351. [CrossRef]

10. Liu, Y.; Key, J.; Tschudi, M.; Dworak, R.; Mahoney, R.; Baldwin, D. Validation of the Suomi NPP VIIRS ice surface temperature environmental data record. Remote Sens. 2015, 7, 17258-17271. [CrossRef]

11. Hall, D.K.; Box, J.E.; Casey, K.A.; Hook, S.J.; Shuman, C.A.; Steffen, K. Comparison of satellite-derived and in-situ observations of ice and snow surface temperatures over greenland. Remote Sens. Environ. 2008, 112, 3739-3749. [CrossRef]

12. Shuman, C.A.; Hall, D.K.; DiGirolamo, N.E.; Mefford, T.K.; Schnaubelt, M.J. Comparison of near-surface air temperatures and modis ice-surface temperatures at summit, greenland (2008-13). J. Appl. Meteorol. Climatol. 2014, 53, 2171-2180. [CrossRef]

13. Comiso, J.C. Surface temperatures in the polar-regions from nimbus-7 temperature humidity infrared radiometer. J. Geophys. Res. Oceans 1994, 99, 5181-5200. [CrossRef]

14. Yu, Y.; Rothrock, D.A.; Lindsay, R.W. Accuracy of sea-ice temperature derived from the advanced very high-resolution radiometer. J. Geophys. Res. Oceans 1995, 100, 4525-4532. [CrossRef]

15. Liu, Y.; Key, J.; Mahoney, R. Sea and freshwater ice concentration from VIIRS on Suomi NPP and the future JPSS satellites. Remote Sens. 2016, 8, 523. [CrossRef]

16. Wang, X.; Key, J.; Liu, Y. A thermodynamic model for estimating sea and lake ice thickness with optical satellite data. J. Geophys. Res. Oceans 2010, 115, C12035. [CrossRef]

17. Serreze, M.C.; Schnell, R.C.; Kahl, J.D. Low-level temperature inversions of the eurasian arctic and comparisons with soviet drifting station data. J. Clim. 1992, 5, 615-629. [CrossRef]

18. Dozier, J.; Warren, S.G. Effect of viewing angle on the infrared brightness temperature of snow. Water Resour. Res. 1982, 18, 1424-1434. [CrossRef]

19. Kneizys, F.X.; Shettle, E.P.; Abreu, L.W.; Chetwynd, J.H.; Anderson, G.P. Users Guide to Lowtran 7; Air Force Geophysics Lab: Hanscom AFB, MA, USA, 1988.

20. Studinger, M.; Koenig, L.; Martin, S.; Sonntag, J. Operation icebridge: Using instrumented aircraft to bridge the observational gap between icesat and icesat-2. In Proceedings of the 2010 IEEE International Geoscience and Remote Sensing Symposium, Honolulu, HI, USA, 25-30 July 2010; pp. 1918-1919.

21. Kurtz, N.; Harbeck, J. Operation Icebridge Sea Ice Freeboard, Snow Depth, and Thickness Data Products Manual, Version 2 Processing; Technique Report; NSIDC: Boulder, CO, USA, 2015.

22. Bennett, R.; Studinger, M. IceBridge KT19 IR Surface Temperature, Version 1. [2013-2017]; NASA National Snow and Ice Data Center Distributed Active Archive Center: Boulder, CO, USA, 2012; Updated 2018.

23. Hutchison, K.D.; Roskovensky, J.K.; Jackson, J.M.; Heidinger, A.K.; Kopp, T.J.; Pavolonis, M.J.; Frey, R. Automated cloud detection and classification of data collected by the visible infrared imager radiometer suite (VIIRS). Int. J. Remote Sens. 2005, 26, 4681-4706. [CrossRef]

24. Berk, A.; Anderson, G.P.; Acharya, P.K.; Bernstein, L.S.; Muratov, L.; Lee, J.; Fox, M.J.; Adler-Golden, S.M.; Chetwynd, J.H.; Hoke, M.L. Modtran5: A Reformulated Atmospheric Band Model with Auxiliary Species and Practical Multiple Scattering Options. In Proceedings of the SPIE, Remote Sensing of Clouds and the Atmosphere IX, Maspalomas, Canary Islands, Spain, 13-16 September 2004; Volume 5571, pp. 341-348.

25. Han, Y.; Van Delst, P.; Weng, F.; Liu, Q.; Groff, D.; Yan, B.; Chen, Y.; Vogel, R. Current Status of the JCSDA Community Radiative Transfer Model (CRTM). In Proceedings of the 17th International TOVS Study Conference (ITSC-17), Monterey, CA, USA, 14-20 April 2010; pp. 1-20.

26. Hori, M.; Aoki, T.; Tanikawa, T.; Motoyoshi, H.; Hachikubo, A.; Sugiura, K.; Yasunari, T.J.; Eide, H.; Storvold, R.; Nakajima, Y. In-situ measured spectral directional emissivity of snow and ice in the 8-14 $\mu \mathrm{m}$ atmospheric window. Remote Sens. Environ. 2006, 100, 486-502. [CrossRef] 
27. Jiménez-Muñoz, J.C.; Sobrino, J.A.; Skoković, D.; Mattar, C.; Cristóbal, J. Land surface temperature retrieval methods from landsat-8 thermal infrared sensor data. IEEE Geosci. Remote Sens. Lett. 2014, 11, 1840-1843. [CrossRef]

28. Aubry-Wake, C.; Baraer, M.; McKenzie, J.M.; Mark, B.G.; Wigmore, O.; Hellström, R.Å.; Lautz, L.; Somers, L. Measuring glacier surface temperatures with ground-based thermal infrared imaging. Geophys. Res. Lett. 2015, 42, 8489-8497. [CrossRef] 